\title{
Variations of $f_{0} F_{2}$ and GPS total electron content over the Antarctic sector
}

\author{
M. Mosert ${ }^{1}$, L. A. McKinnell ${ }^{2,3}$, M. Gende ${ }^{4}$, C. Brunini ${ }^{4}$, J. Araujo ${ }^{5}$, R. G. Ezquer ${ }^{6,7,8}$, and M. Cabrera ${ }^{6}$ \\ ${ }^{1}$ Instituto de Ciencias Astronómicas, de la Tierra y del Espacio (ICATE)_CONICET, \\ Av. España 1512 (Sur), CC 467, 5400 San Juan, Argentina \\ ${ }^{2}$ Hermanus Magnetic Observatory, Hermanus 7200, South Africa \\ ${ }^{3}$ Department of Physics and Electronics, Rhodes University, Grahamstown 6140, South Africa \\ ${ }^{4}$ FCAG, Observatorio Astronomico, UNLP, Paseo del Bosque 1900, La Plata, Argentina \\ ${ }^{5}$ Instituto Antártico Argentino, Dirección Nacional del Antártico, Cerrito 1248, Ciudad Autónoma de Buenos Aires, Argentina \\ ${ }^{6}$ CIASUR, Facultad Regional Tucumán, Universidad Tecnológica Nacional, Argentina \\ ${ }^{7}$ Laboratorio de Ionósfera, Dpto. de Física, FACET, Universidad Nacional de Tucumán, \\ Av. Independencia 1800, CP 4000, Tucumán, Argentina \\ ${ }^{8}$ Consejo Nacional de Investigaciones Científicas y Tecnológicas (CONICET), Argentina
}

(Received May 31, 2010; Revised November 24, 2010; Accepted January 16, 2011; Online published June 14, 2011)

\begin{abstract}
This paper presents a preliminary analysis of the variations of the critical frequency of the $F_{2}$ region $\left(f_{\mathrm{o}} F_{2}\right)$ and the total electron content (TEC) derived from Global Positioning System (GPS) data. Hourly $f_{\mathrm{o}} F_{2}$ values were scaled from ionograms recorded at San Martin $\left(68.1^{\circ} \mathrm{S}, 293.0^{\circ} \mathrm{E}\right)$ and the TEC values were derived from GPS observations at $\mathrm{O}^{\prime}$ Higgins $\left(63.3^{\circ} \mathrm{S}, 302.5^{\circ} \mathrm{E}\right)$. The database includes measurements obtained under different seasonal and solar activity conditions. The study shows that the daily peak of $f_{0} F_{2}$ occurs around local noon in winter and fall, and in spring a secondary peak is observed around midnight. In summer (January) $f_{\mathrm{o}} F_{2}$ reaches its minimum value around the noon sector while the maximum in the diurnal variation of $f_{\mathrm{o}} F_{2}$ is located in a time sector close to midnight. This behaviour is observed at low and high solar activity. The semiannual anomaly appears around noon at high and low solar activity and the winter anomaly is not observed. The effect of the solar activity is generally observed in every season. The analysis of the GPS TEC measurements in the same region indicates that the diurnal, seasonal and solar activity variations are similar to those observed in the $f_{\mathrm{o}} F_{2}$ values. An analysis of the performance of the IRI model to predict $f_{\mathrm{o}} F_{2}$ is also shown using the two IRI options (URSI and CCIR). The comparisons between the experimental values and the IRI predictions show some discrepancies. Key words: Ionosphere, high latitude, IRI, $f_{\mathrm{o}} F_{2}$, GPS TEC.
\end{abstract}

\section{Introduction}

Three latitudinal regions can be distinguished in the terrestrial ionosphere namely: the equatorial zone (within $20^{\circ}$ of the magnetic equator), the high latitude (poleward of about $60^{\circ}$ geomagnetic) and the middle latitude zone in between.

The knowledge of the high latitude ionosphere is more limited compared with that of the middle and low latitudes and the known features of the high latitude region have been derived mainly from observations in the Northern hemisphere. However marked differences, at the high latitudes between the hemispheres have been observed (Mallis and Essex, 1993).

Key parameters for studying the ionosphere are the critical frequency of the $F_{2}$ region $\left(f_{\mathrm{o}} F_{2}\right)$ and the total electron content (TEC). The $f_{\mathrm{o}} F_{2}$ is equivalent to the maximum density in the vertical distribution of the ionosphere $\left(N_{\mathrm{m}} F_{2}\right)$ and TEC is defined as the number of free electrons in a cylinder of one square metre along the radio path, a parameter that is very important for systems using trans-

Copyright (C) The Society of Geomagnetism and Earth, Planetary and Space Sciences (SGEPSS); The Seismological Society of Japan; The Volcanological Society of Japan; The Geodetic Society of Japan; The Japanese Society for Planetary Sciences; TERRAPUB.

doi:10.5047/eps.2011.01.006 ionospheric radio waves.

The combination of data obtained by different techniques (from ground-based instruments to satellite observations) assists with improving the understanding of the complex phenomena and high variability of the ionosphere at the high latitudes. The increase in availability of total electron content data (TEC) over the last ten years has largely come from a rapid increase in the number of Global Positioning System receiver stations available from which TEC data (GPS TEC) can be derived. Compared with the long record, almost 50 years of ionospheric observations available from ground based measurements, the GPS TEC database is relatively short. However the increase in the number of GPS receiver sites is now providing an important database for studying the ionosphere.

In the Argentine Antarctic sector there are two ionospheric stations: San Martin $\left(68.1^{\circ} \mathrm{S}, 293.0^{\circ} \mathrm{E}\right.$; Geomagnetic: $\left.53.0^{\circ} \mathrm{S}\right)$ and Belgrano $\left(77.9^{\circ} \mathrm{S}, 321.4^{\circ} \mathrm{E}\right.$; Geomagnetic: $\left.67.5^{\circ} \mathrm{S}\right)$. They have been operating for more than four decades and in 1994 the two ionospheric stations were equipped with KEL AEROSPACE IPS 42 ionosondes and a digitized system for the vertical incident soundings. However, as far as the authors of this paper know, there are few published studies using ionosonde data from the Argentine Antarctic region (Mosert et al., 2003). 

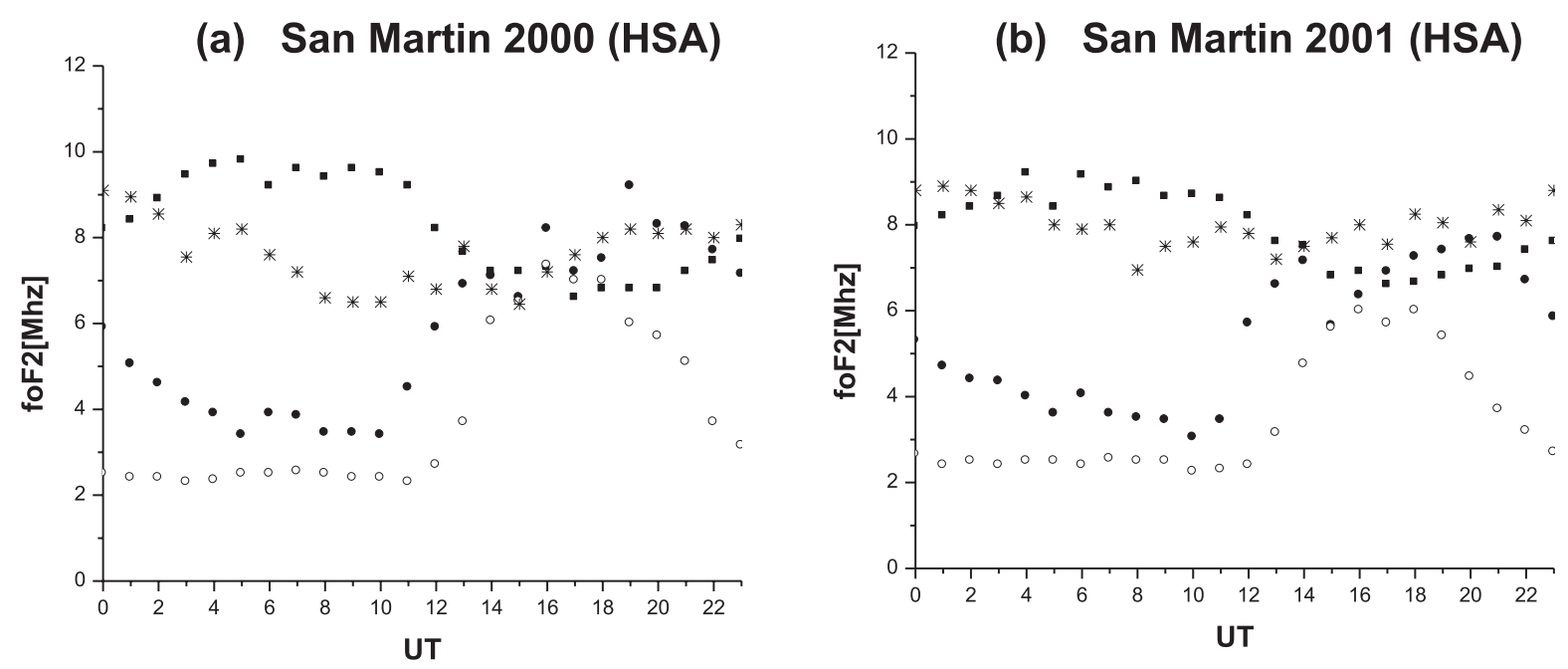

(c) San Martin 2007 (LSA)
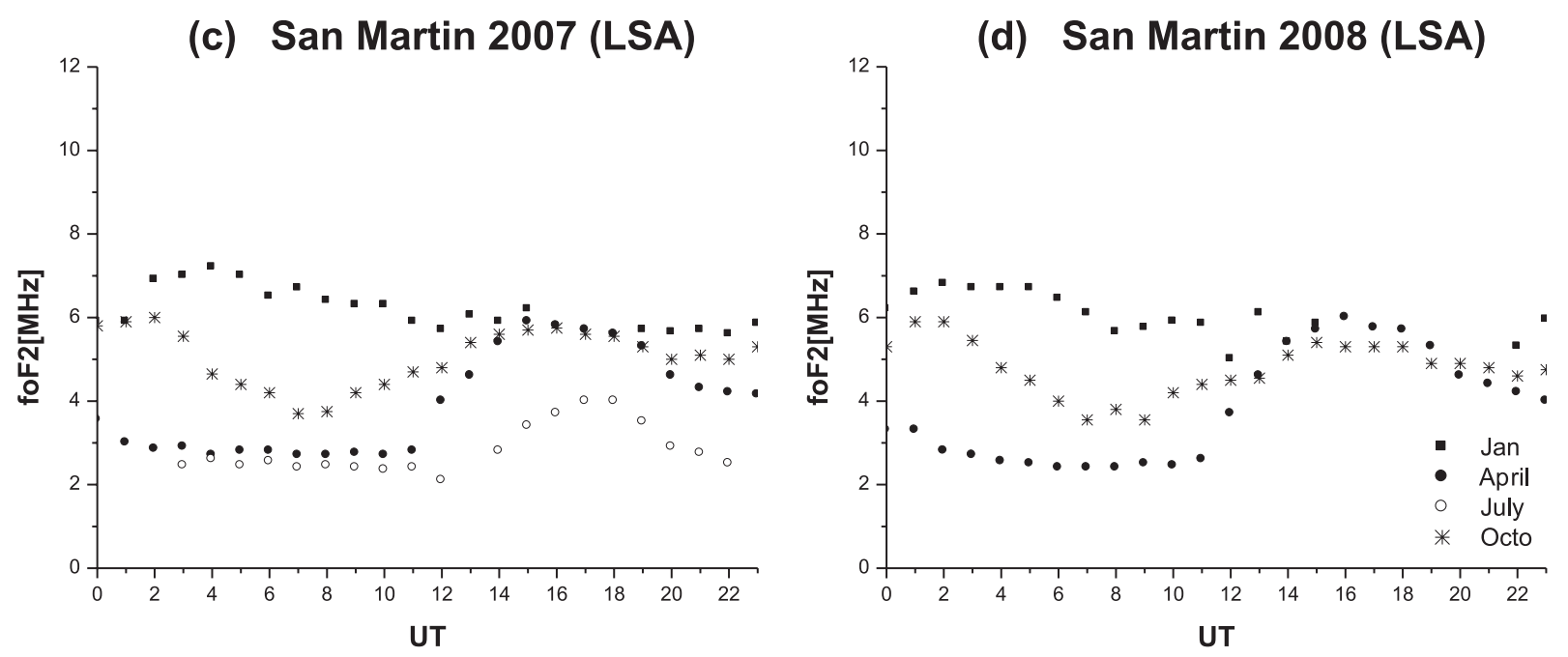

Fig. 1. The monthly median values of $f_{\mathrm{o}} F_{2}$ are plotted against local time for 4 different seasons to illustrate the diurnal and seasonal variations for the years (a) 2000 and (b) 2001 representing high solar activity and (c) 2007 and (d) 2008 representing low solar activity.

The San Martin ionosonde station is located at an high geographic latitude but is a middle-latitude station in terms of geomagnetic coordinates. Belgrano is an auroral station from the geographic and geomagnetic point of view. Both stations offer an excellent opportunity for studying the complex behaviour of this remote region and for contributing the improvement of ionospheric models.

Several empirical models for the middle and high latitude $F$-region exist. One of them is the International Reference Ionosphere (IRI) model (Bilitza, 2001; Bilitza and Reinisch, 2008). It was formulated by the Committee on Space Research (COSPAR) and the International Union of Radio Science (URSI) in the sixties. The model has been validated using a large data base and it is continuously improved taking into account experimental evidence (Bilitza, 2001; Bilitza and Reinisch, 2008). Authors of this paper have validated the IRI model using ionospheric data from low and middle latitudes (Ezquer et al., 1996, 1997, 1998, 1999; Mosert et al., 2004).

The aim of this contribution is to analyze the variations of the critical frequency of the ionospheric $F_{2}$ region $\left(f_{\mathrm{o}} F_{2}\right)$ equivalent to the maximum electron density $\left(N_{\mathrm{m}} F_{2}\right)$ and the total electron content derived from GPS observations (GPS TEC), using the new database from the Antarctic region as a first step towards contributing to the characterisation of the ionospheric behaviour in this geographic area. The ability of the IRI model to predict $f_{\mathrm{o}} F_{2}$ over the Argentine Antarctic region is also investigated and presented in this paper.

\section{Data Used}

The study was made using two Antarctic stations situated close to each other: San Martin (68.1 S, 293.0 E; Geomagnetic $53.0^{\circ} \mathrm{S}$ ) for the $f_{\mathrm{o}} F_{2}$ measurements and $\mathrm{O}^{\prime}$ Higgins (63.3 S, $302.5 \mathrm{E}$; Geomagnetic: $\left.48.6^{\circ} \mathrm{S}\right)$ for the GPS TEC values. The $f_{\mathrm{o}} F_{2}$ measurements were recorded with an ionosonde (KEL Aeropace) and the TEC values were obtained from Global Positioning System (GPS) data. The GPS TEC values were derived from GPS slant TEC observations using the LPIM algorithm developed by the Argen- 
(a) Great Wall 1996 (LSA)

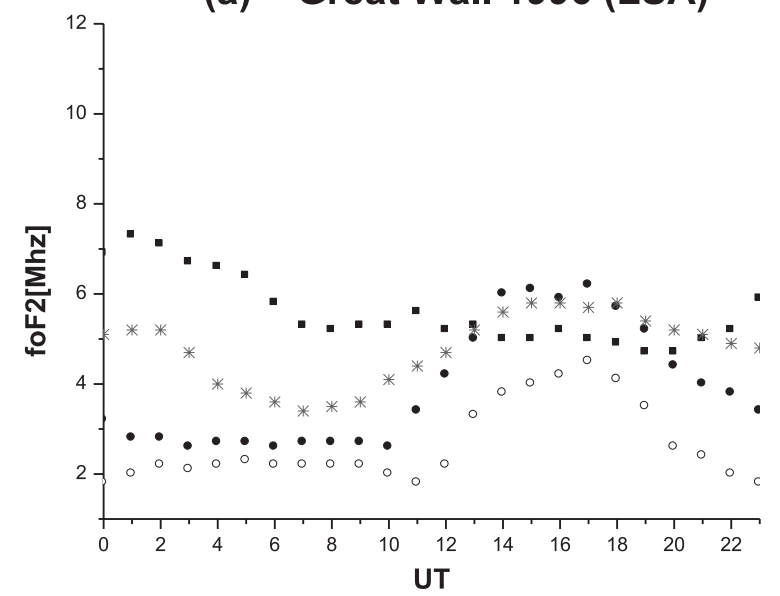

(c) San Martin 1996 (LSA)

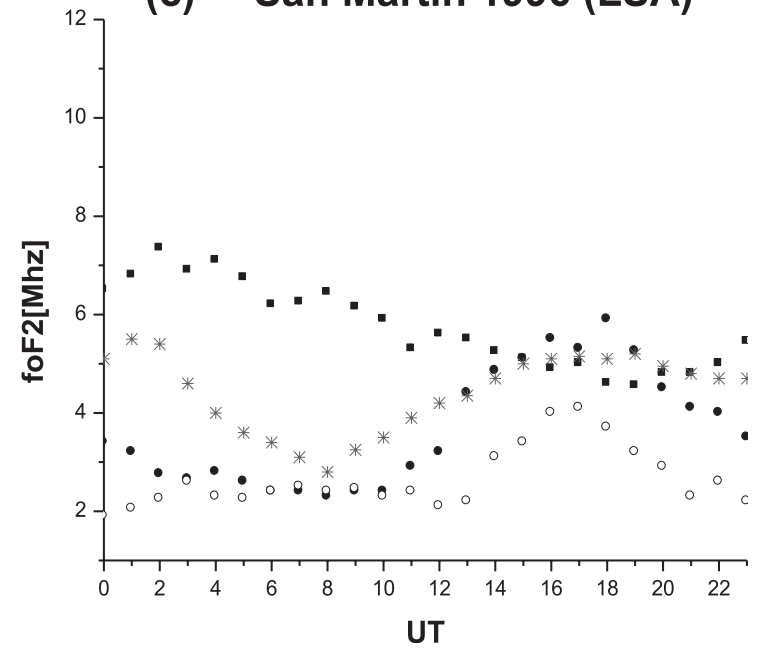

(b) Great Wall 1997 (LSA)

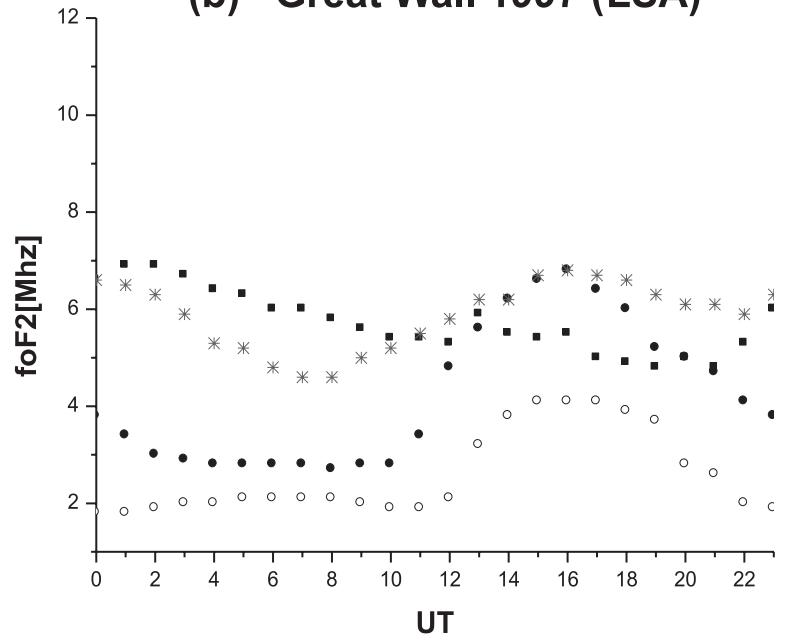

(d) San Martin 1997 (LSA)

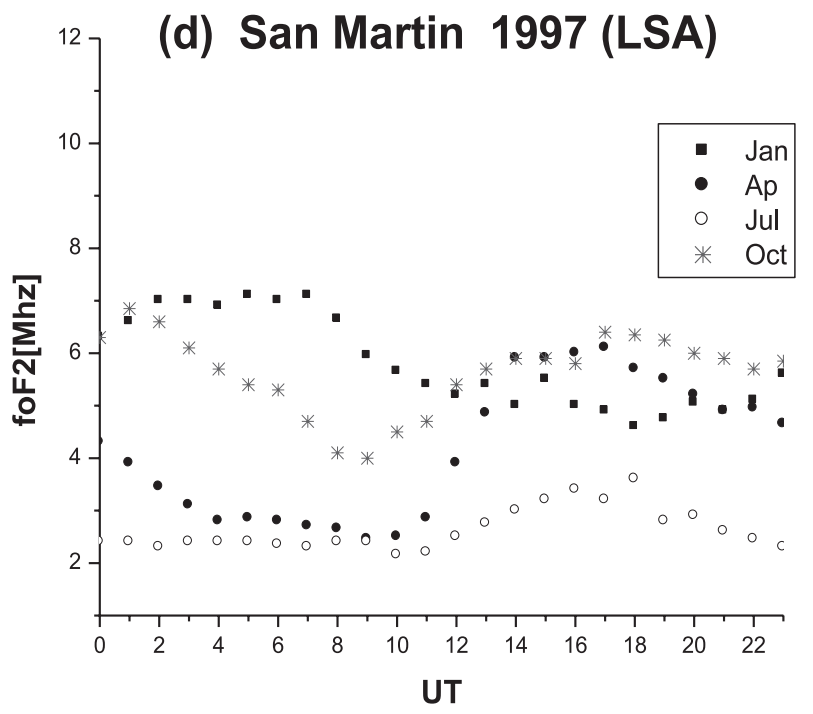

Fig. 2. The $f_{\mathrm{o}} F_{2}$ median values for Great Wall: (a) $1996\left(R_{z 12}=9\right)$, (b) $1997\left(R_{z 12}=23\right)$, and for San Martin: (c) 1996, (d) 1997. The seasons are represented by January (summer), April (fall), July (winter) and October (spring).

tine La Plata Group (Brunini et al., 2001). As it is known GPS TEC represents a measurement of TEC up to around $20000 \mathrm{~km}$ (height of the GPS satellites), including the major part of the plasmaspheric electron content.

The data base includes hourly monthly median values of $f_{\mathrm{o}} F_{2}$ and GPS TEC obtained during the representative months of summer (January), winter (July), fall (April) and spring (October) during high solar activity (HSA) years: $2000\left(R_{z 12}=117\right), 2001\left(R_{z 12}=111\right)$ and low solar activity (LSA) years: $2007\left(R_{z 12}=8\right), 2008\left(R_{z 12}=3\right)$. In addition, median $f_{\mathrm{o}} F_{2}$ values obtained at San Martin and Great Wall $\left(77.7^{\circ} \mathrm{S}, 318.5^{\circ} \mathrm{E}\right.$; Geomagnetic: $\left.67.2^{\circ} \mathrm{S}\right)$ during the LSA years $1996\left(R_{z 12}=9\right)$ and $1997\left(R_{z 12}=23\right)$ were also used.

It is important to remember that at high latitudes all ionosondes are subject to several rather severe limitations during space weather events such as, magnetic storms and sub-storms and associated auroral and polar absorption, auroral events, spread $F$ conditions and sporadic $E$ layer effects which can produce a blanketing of the signal trace.
For this reason it is particularly important for the ionospheric data to be manually edited prior to use. The KEL Aerospace ionosonde does not allow automatic scaling of the ionograms, and therefore, all data used in this analysis was selected to be quality and manually scaled. For this reason we have included in our analysis only data from San Martin station.

\section{Analysis of the Results}

3.1 Behaviour of $f_{0} F_{2}$

In Fig. 1 the median values of $f_{\mathrm{o}} F_{2}$ are plotted against the local time (LT) for the 4 different seasons to illustrate the diurnal and seasonal variations for the years (a) 2000 and (b) 2001 representing the HSA period and the years (c) 2007 and (d) 2008 representing the low solar activity period. It can be observed that at the LSA and HSA periods the daily $f_{\mathrm{o}} F_{2}$ peak over the San Martin station occurs around the local noon and the minimum values around sunrise in winter and fall. In spring a secondary peak is observed around midnight (this is more evident at LSA than at HSA). Differ- 

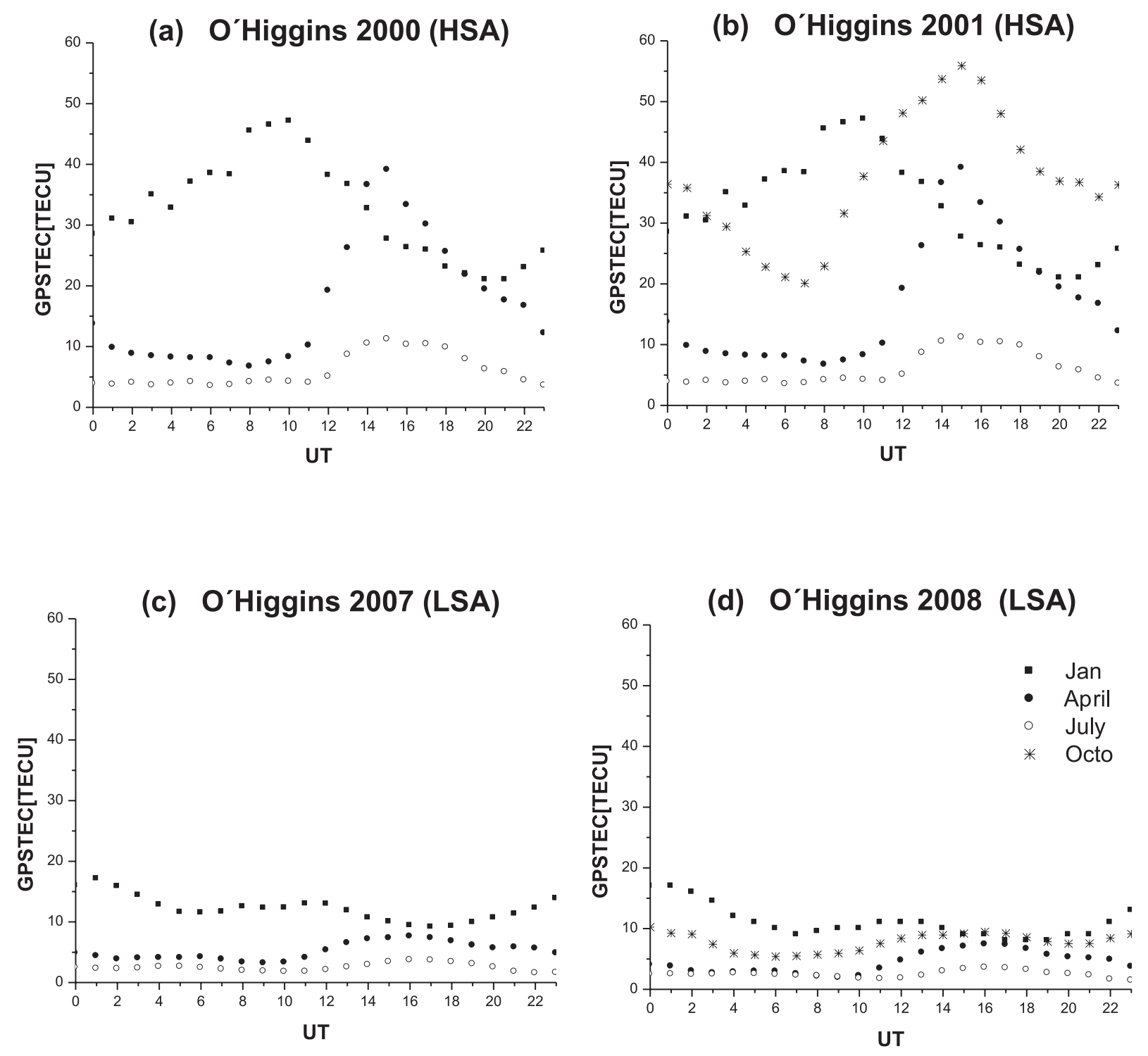

Fig. 3. The monthly median values of GPS TEC are plotted against local time 4 different seasons to illustrate the diurnal and seasonal variations for the years (a) 2000 and (b) 2001 representing high solar activity and (c) 2007, (d) 2008, representing low solar activity.

ent behaviour is observed in summer for both solar activity levels: the maximum value of the $F_{2}$-layer is not observed close to noon but in a time sector close to midnight. Furthermore, the minimum value of the parameter is observed mainly close to noon. This behaviour is found at LSA and HSA. The anomalous diurnal variation in $f_{\mathrm{o}} F_{2}$ was also reported by Sojka et al. (1988) and Pavlov et al. (2008) using data from the Argentine Islands ionosonde station $\left(65.2^{\circ} \mathrm{S}\right.$, $\left.295.7^{\circ} \mathrm{E}\right)$. It is important to point out that this anomalous diurnal variation was also observed in the Southern Hemisphere and it is known as the Weddell Sea Anomaly in $N_{\mathrm{m}} F_{2}$ (Horvath, 2007). This behaviour indicates that diurnal variations of $f_{\mathrm{o}} F_{2}$ have a weak solar zenith dependence. These diurnal variations of $f_{\mathrm{o}} F_{2}$ are explained by Pavlov and Pavlova (2009) by changes in the neutral wind-induced drift along the magnetic field lines and by neutral density variations. A poleward neutral wind causes a lowering of the $F_{2}$-region height and a reduction of the density peak $N_{\mathrm{m}} F_{2}$ due to an increase in the loss rate of $\mathrm{O}^{+}$ions with $\mathrm{N}_{2}$ and $\mathrm{O}_{2}$. An equatorward wind tends to increase the value of $N_{\mathrm{m}} F_{2}$ by transporting the plasma up along field lines to regions of lower loss of $\mathrm{O}^{+}$. Close to the noon sector, the $F_{2}$ layer is lowered into an altitude of higher recombination rates of $\mathrm{O}^{+}$causing a decreasing of $N_{\mathrm{m}} F_{2}$. Close to the midnight sector, the $F_{2}$-layer is raised and maintained by plasma drift. As the ionosphere is sunlit during the long summer day in January $N_{\mathrm{m}} F_{2}$ increases producing the observed higher $N_{\mathrm{m}} F_{2}$ values close to midnight (Pavlov et al., 2008; Pavlov and Pavlova, 2009).

The results of Fig. 1 also illustrates that in the HSA period the winter anomaly is slightly present in the year 2000 during post noon hours (13.00 and 14.00 LT) and it is not observed in the year 2001. In 2007 (in 2008 are missing the winter $f_{\mathrm{o}} F_{2}$ values) the $f_{\mathrm{o}} F_{2}$ summer-winter differences around noon are more pronounced than in the years of HSA (2000-2001). These results indicate that the winter anomaly decays in amplitude or it is not present with decreasing solar activity (Torr and Torr, 1973).

Torr and Torr (1973) studying the winter anomaly by using noon monthly median values data of $f_{\mathrm{o}} F_{2}$ for a chain of 
(a) January 2000 (HSA)

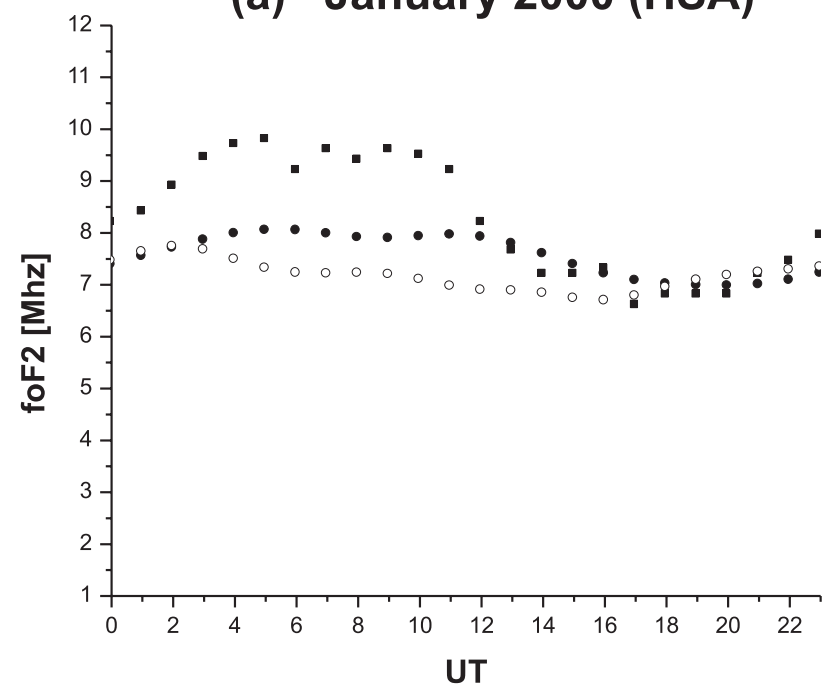

(c) July 2000 (HSA)

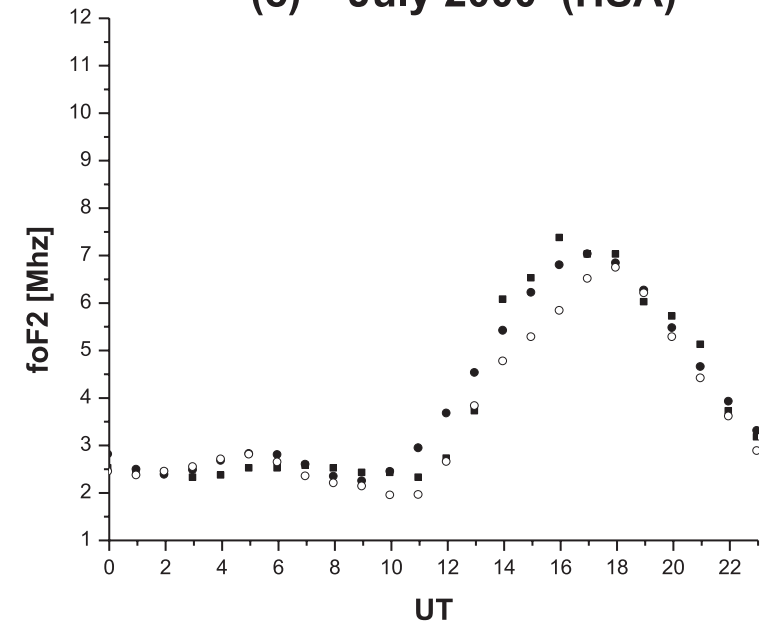

(b) April 2000 (HSA)

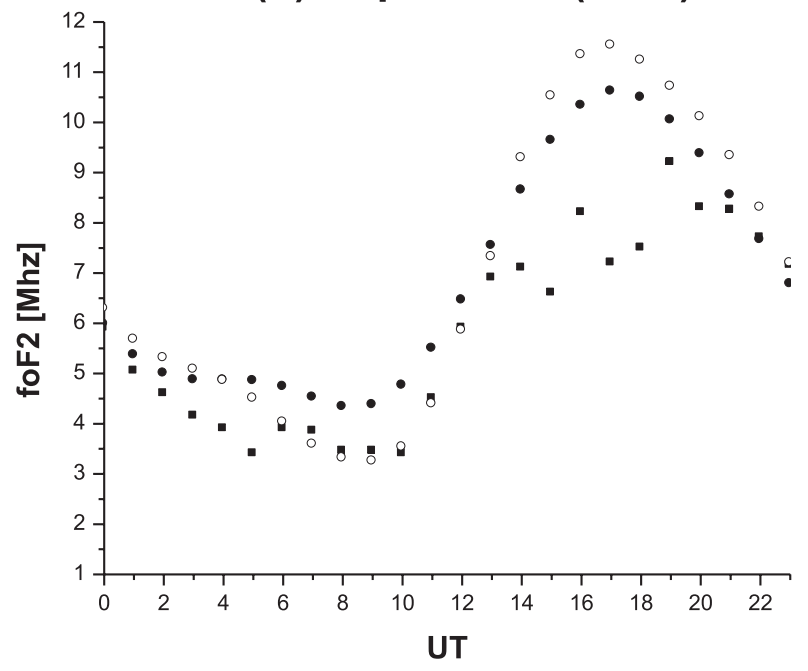

(d) October 2000 (HSA)

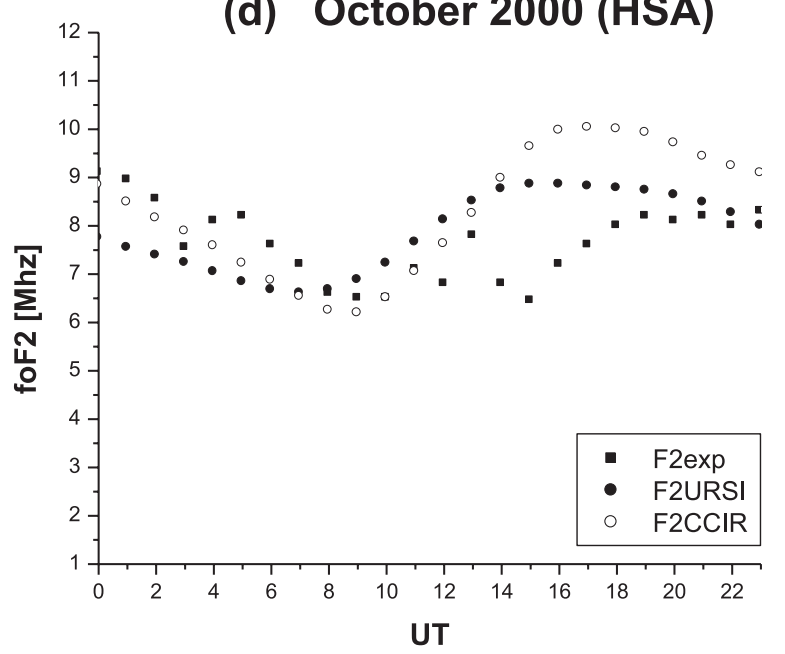

Fig. 4. The $f_{\mathrm{o}} F_{2}$ monthly median values for San Martin during a high solar activity year (2000) are plotted against local time for the different seasons together with the IRI predicted $f_{\mathrm{o}} F_{2}$ values (CCIR and URSI). The seasons are represented by (a) January for Summer, (b) April for Fall, (c) July for Winter and October for Spring.

stations over the globe under different solar activity conditions, concluded that the winter anomaly is more pronounced in the Northern Hemisphere than in the Southern Hemisphere and the magnitude of the winter anomaly decrease with decreasing solar activity.

Other feature of the seasonal variation of $f_{\mathrm{o}} F_{2}$ is the semi-annual anomaly that it is characterized by maximum values of $f_{\mathrm{o}} F_{2}$ around noon in the equinoctial months. It can be seen in Fig. 1 that the spring and fall values of $f_{\mathrm{o}} F_{2}$ around noon are generally greater than the winter and summer $f_{\mathrm{o}} F_{2}$ values.

The analysis of Fig. 1 also illustrates that in summer, spring and fall the median values of $f_{\mathrm{o}} F_{2}$ are greater at high solar activity than at low solar activity during all the hours of the day. The values range between 2.3 and $9.8 \mathrm{Mhz}$ during the HSA years and between 2.1 and 7.2 Mhz during the LSA years. In winter this behaviour is observed only between 08.00 LT and 18.00 LT. From 00.00 LT and 07.00 LT the effect of the solar activity on $f_{\mathrm{o}} F_{2}$ is not observed.
Figure 2 shows the monthly median values of $f_{\mathrm{o}} F_{2}$ for Great Wall and San Martin during the LSA years: 1996 and 1997 and for the 4 seasons. It can be seen that the diurnal and seasonal variations are similar to those observed in Fig. 1. Particularly, it is observed the absence of the winter anomaly, the presence of the equinoctial peaks around noon and the anomalous diurnal variations of $f_{\mathrm{o}} F_{2}$ in summer (the maximum value is displaced from the expected noon sector to a sector close to midnight).

\subsection{Behaviour of GPS TEC}

In Fig. 3 the monthly median values TEC values (in TEC units of $10^{16} \mathrm{e} / \mathrm{m}^{2}$ ) derived from GPS observations (GPS TEC) are plotted against the time for the 4 different seasons to illustrate the diurnal and seasonal variations for the years (a) 2000 and (b) 2001 representing the high solar activity and (c) 2007 and (d) 2008 representing the low solar activity. Note that in Fig. 3 (a) and (c) are missing the spring values.

The analysis of the observed GPS TEC values in the close 

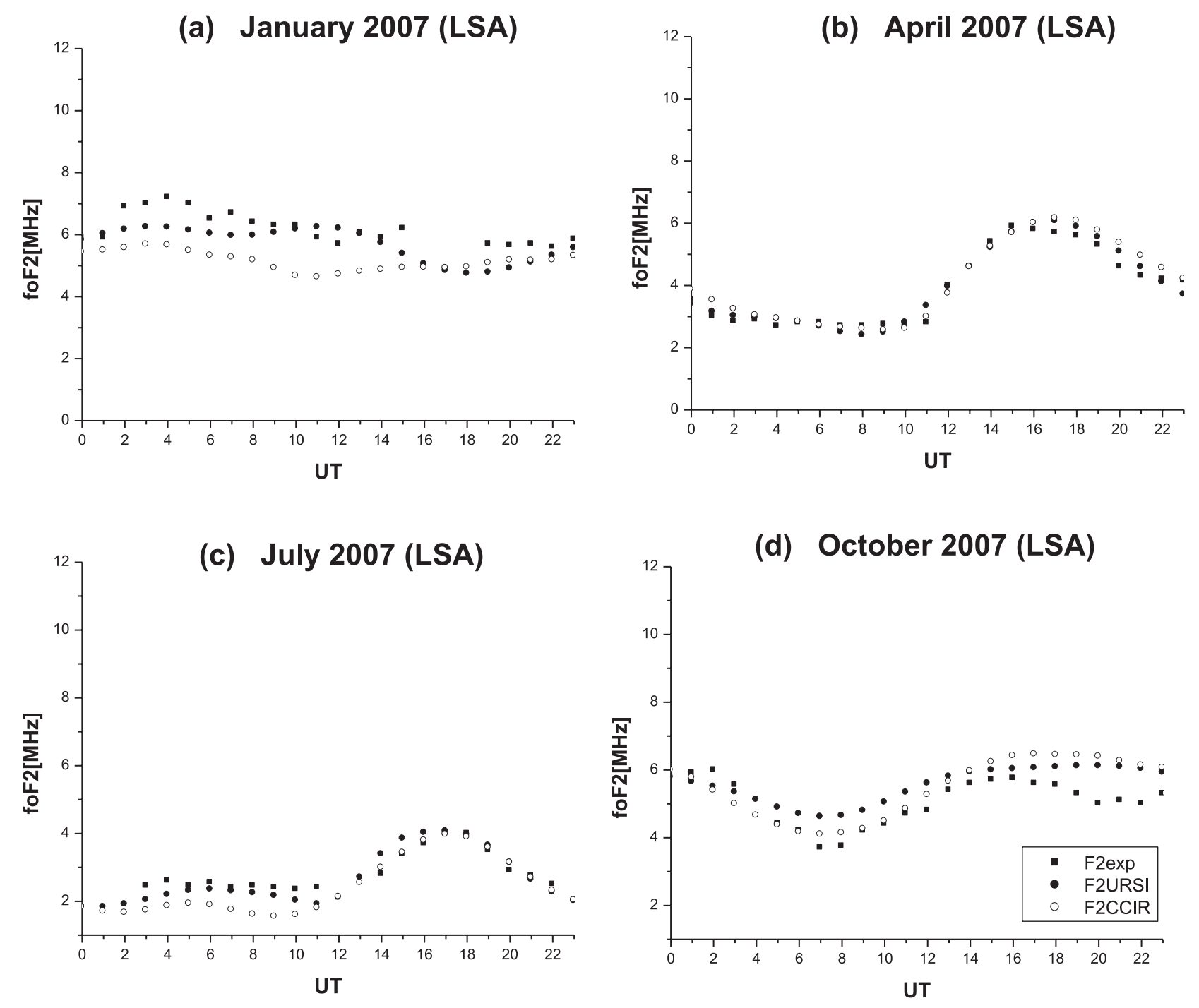

Fig. 5. The $f_{\mathrm{o}} F_{2}$ monthly median values for San Martin during a low solar activity year 2007 are plotted against local time for the different seasons together with the IRI predicted $f_{\mathrm{o}} F_{2}$ values (CCIR and URSI). The seasons are represented by (a) January for Summer, (b) April for Fall, (c) July for Winter and (d) October for Spring.

region where the $f_{\mathrm{o}} F_{2}$ values were measured indicates that the diurnal, seasonal and solar activity behaviour is similar to that observed in the $f_{\mathrm{o}} F_{2}$ values. The anomalous diurnal variations of $f_{\mathrm{o}} F_{2}$ observed in summer are also found in the corresponding GPS TEC values (the daytime observations are lower than the night-time values). The winter anomaly is not present (the GPS TEC measurements are greater in summer than in winter in the LSA and HSA years). The semi-annual anomaly around noon is generally present in all the years. The only exception is in 2007 (where the spring values are missing). The effect of the solar activity on the GPS TEC values is also observed: the values range between 2 and 17 TECU at LSA and between 4 and 55 TECU at HSA.

As it is known GPS TEC represents a measurement of TEC up to around $20000 \mathrm{~km}$ (height of the GPS satellites), including the ionospheric TEC (bottom and topside) and the plasmaspheric TEC. Nevertheless, previous studies (Belehaki et al., 2003, 2004; Mosert et al., 2007) that analyze the behaviour of TEC obtained by GPS observations and the ionospheric TEC obtained with the technique pro- posed by Huang and Reinisch (2001) show that the seasonal and solar activity variations of GPS TEC follow very well the corresponding ionospheric TEC variations.

\subsection{Comparison between $f_{0} F_{2}$ measurements and the IRI model}

Figure 4 shows the comparison between the $f_{\mathrm{o}} F_{2}$ monthly median values for San Martin and the two options (URSI and CCIR) provided by the IRI model (Bilitza and Reinisch, 2008) to predict the density peak $f_{\mathrm{o}} F_{2}$ during a high solar activity year (2000). The seasons are represented by (a) January for summer, (b) April for fall, (c) July for winter and (d) October for spring. Figure 5 shows the same comparisons for a year of low solar activity (2007).

It can be seen that, in general, the two models estimations (CCIR and URSI) follow the diurnal trend of the experimental $f_{\mathrm{o}} F_{2}$ curves in winter (July) and fall (April): lower values are observed during night-time than during daytime in the three curves at both levels of solar activity. In generally the IRI predictions overestimate the observations during April at HSA and a good agreement is observed during LSA. In spring (October) the IRI predictions do not 
reproduced the post sunset peak observed in the experimental values. The model overestimation is also present in this month particularly at HSA. In summer (January) the diurnal variation observed in $f_{\mathrm{o}} F_{2}$ is not predicted by the model at HSA: The night time maximum is not reproduced by the IRI predictions. It is important to point out that in this season during night-time the URSI values are closer to the observations than the CCIR IRI option values. Moreover it is noted that the night/day differences are more pronounced in the measurements than in the IRI predictions. This is more evident at HSA.

\section{Summary}

Using ionosonde observations at San Martin $\left(68.1^{\circ} \mathrm{S}\right.$; 293. $0^{\circ}$ E geographic; $53^{\circ} \mathrm{S}$ magnetic) and GPS observations at $\mathrm{O}^{\prime}$ Higgins $\left(63.3^{\circ} \mathrm{S}, 302.5^{\circ} \mathrm{E}\right.$; magnetic $\left.48.6^{\circ} \mathrm{S}\right)$, hourly monthly median values of $f_{\mathrm{o}} F_{2}$ (critical frequency of the $F_{2}$ region) and GPS TEC (vertical GPS total electron content) have been derived. The diurnal, seasonal and solar activity variations of both parameters in this Antarctic region have been analyzed. The study shows that the daily peak of $f_{\mathrm{o}} F_{2}$ occurs around local noon in winter and fall, in spring a secondary peak is observed around midnight (this is more evident at LSA than at HSA). In summer (January) $f_{\mathrm{o}} F_{2}$ reaches its minimum value around the noon sector while the maximum in the diurnal variation of $f_{\mathrm{o}} F_{2}$ is located in a time sector close to midnight. This behaviour is observed at low and high solar activity. The seasonal variations of $f_{\mathrm{o}} F_{2}$ indicate that the winter anomaly is slightly present at HSA and it is not observed in the LSA years, and that the semi-annual anomaly occurs in all the cases analyzed. Our analysis also illustrates that in summer, spring and fall the median values of $f_{\mathrm{o}} F_{2}$ are greater at high solar activity than at low solar activity during all the hours of the day. The values range between 2.3 and $9.8 \mathrm{Mhz}$ during the HSA years and between 2.1 and 7.2 Mhz during the LSA years. In winter this behaviour is observed only between 08.00 LT and 18.00 LT. From 00.00 LT and 07.00 LT the effect of the solar activity on $f_{\mathrm{o}} F_{2}$ is not observed.

It is important to point out that this analysis is a first attempt to analyze ionospheric parameters using data from the Argentine Antarctic region. An extension of this study is being done using data from the Belgrano station and parameters derived from electron density profiles.

Although the results here presented are preliminary we consider important to report them in order to show that the observational database in this remote region can help to describe better the morphology and modelling of the high latitude ionosphere particularly in the Southern Hemisphere.

Acknowledgments. This work was made possible by a bilateral grant project "Polar Ionospheric Characterisation" funded by the Ministery of Science, Technology and Productive Innovation (MINCyT) of Argentina and the National Research Fundation
(NRF) of South Africa. The authors also want to thank to Dr. A. Foppiano who provided the data from the Great Wall station.

\section{References}

Belehaki, A., N. Jakowski, and B. W. Reinisch, Comparison of ionospheric ionization measurements over Athens using ground ionosonde and GPS derived TEC values, Radio Sci., 38(6), 1105, 2003.

Belehaki, A., N. Jakowski, and B. W. Reinisch, Plasmaspheric electron content derived from GPS TEC and digisonde ionograms, Adv. Space Res., 33, 833-837, 2004.

Bilitza, D., International Reference Ionosphere 2000, Radio Sci., 36, 261275, 2001.

Bilitza, D. and B. W. Reinisch, International Reference Ionosphere: Improvements and new parameters, Adv. Space Res., 42(4), 599-609, 2008.

Brunini, C., A. Meza, and A. Diaz, Regional vertical total electron content using GPS observation, Proceedings of the 2001 IAG Scientific Assembly (CD edition), Budapest, Hungary, 2001.

Ezquer, R. G., R. Del V. Oviedo, and C. Jadur, Ionospheric predictions for South American latitudes, Radio Sci., 31(2), 381-388, 1996.

Ezquer, R. G., N. Jakowski, and C. Jadur, Predicted and measured total electron content over Havana, J. Atmos. Sol.-Terr. Phys., 59(5), 591596, 1997.

Ezquer, R. G., C. Jadur, and M. Mosert, IRI-95 TEC predictions for the South American peak of the equatorial anomaly, Adv. Space Res., 59(5), 811-814, 1998.

Ezquer, R. G., M. A. Cabrera, and J. R. Manzano, Predicted and measured electron density at $600 \mathrm{~km}$ altitude in the South American peak of the equatorial anomaly, J. Atmos. Sol. Terr. Phys., 61(5), 415-421, 1999.

Horvath, I., Impact of 10 January 1997 geomagnetic storm on the night-time Weddell Sea Anomaly: A study utilizing data provided by the TOPEX/Poseidon mission and the Defense Metereological Satellite Program, and simulations generated by the Coupled Termosphere/Ionosphere Plasmasphere model, J. Geophys. Res., 112, A06329, doi:10.1029/2006JA012153, 2007.

Huang, X. and B. W. Reinisch, Vertical electron content from ionograms in real time, Radio Sci., 22(6), 335-342, 2001.

Mallis, M. and E. A. Essex, Diurnal and seasonal variability of the southern-hemisphere main ionospheric trough from differential-phase measurements, J. Atmos. Terr. Phys., 55, 1021, 1993.

Mosert, M., R. G. Ezquer, G. Miro, B. Lazo, and L. de la Zerda, A preliminary analysis of the variability of ionospheric characteristics, Proceedings of the IRI Task Force Activity 2002, IC/IR/2003/3, pag. 17, ISBN 9295003 18-7, Triste Italy, 2003.

Mosert, M., D. Buresova, R. G. Ezquer, and G. Mansilla, Behaviour of the bottomside electron density profile over Pruhonice, Adv. Space Res., 34(9), 1982-1989, 2004.

Mosert, M., M. Gende, C. Brunini, R. G. Ezquer, and D. Altadill, Comparisons of IRI TEC predicitons with GPS and digisonde measurements at Ebro, Adv. Space Res., 39, 841-847, 2007.

Pavlov, A. V. and N. M. Pavlova, Anomalous variations of NmF2 over the Argentine Islands: a statical study, Ann. Geophys., 27, 1363-1375, 2009.

Pavlov, A. V., N. M. Pavlova, S. F. Makarenko, and V. N. Shubin, Anomalous variation in the structure of the ionospheric F2 region at geomagnetic midlatitudes of the Southern and Northern hemispheres in going from summer conditions at high solar activity, Geomag. Aeron., 48, 75$88,2008$.

Sojka, J. J., R. W. Schunk, and G. L.Wrenn, A comparison of foF2 obtained from a time-dependent ionospheric model with Argentine Islands data for quiet conditions, J. Atmos. Terr. Phys., 50, 1027-1039, 1988.

Torr, D. G. and M. R. Torr, The seasonal behaviour of the F2 layer of the ionosphere, J. Atmos. Terr. Phys., 35, 2237-2251, 1973.

M. Mosert (e-mail: mmosert@icate-conicet.gob.ar), L. A. McKinnell, M. Gende, C. Brunini, J. Araujo, R. G. Ezquer, and M. Cabrera 